\title{
Manejo do Solo e da Irrigação no Controle de Meloidogyne incognita em Cultivo Protegido
}

\author{
Marcos R. Dutra ${ }^{1}$, Vicente P. Campos ${ }^{2}$, Fernando S. Rocha ${ }^{2}$, \\ Juliana R. C. Silva ${ }^{3} \&$ Edson A. Pozza ${ }^{2}$
}

\begin{abstract}
${ }^{1}$ Syngenta Proteção de Cultivos Ltda, CEP 38408-188, Uberlândia, MG, e-mail: marcos.dutra@syngenta.com.br; ${ }^{2}$ Universidade Federal de Lavras, Departamento de Fitopatologia, Cx. Postal 3037, CEP 37200-000, Lavras, MG, e-mail: rocha.fs@bol.com.br; ${ }^{3}$ Universidade de Rio Verde, Departamento de Agronomia, Cx. Postal 104, CEP 75901-970, Rio Verde, GO, e-mail: jrcampos@fesurv.br
\end{abstract}

(Aceito para publicação em 28/07/2006)

Autor para correspondência: Fernando S. Rocha

DUTRA, M.R., CAMPOS, V.P., ROCHA, F.S., SILVA, J.R.C. \& POZZA, E.A. Manejo do solo e da irrigação no controle de Meloidogyne incognita em cultivo protegido. Fitopatologia Brasileira 31:405-407. 2006.

\begin{abstract}
RESUMO
A flutuação populacional de juvenis do segundo estádio (J2) de M. incognita e sua infectividade foram estudadas por meio de bioteste em solo revolvido com ou sem irrigação, comparadas a condições de solo não revolvido nem irrigado, considerado testemunha, e com apenas irrigado, em casa-de-vegetação por 14 dias. Aos sete dias, a população de J2 no solo foi significativamente reduzida apenas nas parcelas revolvidas. Entretanto, a infectividade do inóculo no solo nesse período, avaliada em bioteste, foi reduzida apenas nas parcelas revolvidas e irrigadas. Aos 14 dias, a população de J2 no solo foi menor nas parcelas revolvidas com ou sem irrigação, porém continuou sendo a mais baixa nas parcelas apenas revolvidas. Contudo, a infectividade do inóculo no solo neste período foi mais baixa nas parcelas revolvidas e irrigadas e mais elevada na testemunha.
\end{abstract}

Palavras-chaves adicionais: Meloidogyne incognita, privação alimentar, infectividade, nematóide de galhas, controle de fitonematóides, cultivo protegido.

\begin{abstract}
Soil and water management in the control of Meloidogyne incognita in greenhouse

The population fluctuation of second-stage juveniles (J2) of $M$. incognita and their infectivity assessed by biotest were studied in the greenhouse, using plowed soil, irrigated or not, compared to control (unplowed and unirrigated) and to plots irrigated only, for 14 days. At seven days, the $\mathrm{J} 2$ population in the soil was significantly reduced only in plowed plots. However, the soil inoculum infectivity, in this period, was reduced only in plowed and irrigated plots. At 14 days, the J2 population in the soil was lower in plowed plots with or without irrigation, but lowest in plots only plowed.The infectivity of soil inoculum, in this period, was lowest in plowed and irrigated soil and highest in the control.

Additional keywords: Meloidogyne incognita, starvation, infectivity, root-knot nematodes, control of plant parasitic nematodes.
\end{abstract}

O cultivo comercial de hortaliças em estufas plásticas é atividade consolidada e crescente, especialmente nas proximidades das grandes aglomerações urbanas. A capacidade de produçãointensiva emestufas atendeàdemanda desses locais, tanto em quantidade quanto em qualidade de produtos hortifrutigranjeiros. A cobertura plástica evita danos causados por chuvas torrenciais, além de manter boas condições de temperatura durante todo o ano e proporcionar ganho térmico nas temperaturas do ar e do solo (Buriol et al., 1993; Schneider et al., 1993). Por outro lado, o cultivo intensivo leva ao aumento das populações dos nematóides das galhas (Madulu \& Trudgill, 1994), obrigando o produtor a implementar táticas de controle para produzir hortaliças de qualidade. $\mathrm{O}$ controle de doenças através do uso de produtos químicos e programas preventivos podem ser eficientes, entretanto, são onerosos e concorrem negativamente para a imagem dos produtos nematicidas (Medeiros et al., 2001). A recomendação de controle através do plantio de cultura sem interesse econômico não interessa ao produtor, além disto é necessário produzir hortaliças sem agrotóxicos. Com esse intuito, muitos pesquisadores buscam alternativas de controle para viabilizar o uso desta área economicamente. $\mathrm{O}$ alqueive de curta duração, isto é, por 30 a 45, dias tem propiciado boas reduções de populações de Meloidogyne spp. (Di Vito \& Carella, 1985; Campos, 1987). A manipulação da umidade em ambiente de temperatura elevada, durante certo período, pode reduzir o poder infectante do inóculo no solo (Dutra \& Campos, 2003a). Este manejo, portanto, poderá constituir técnicas de controle no futuro. Desta forma, objetivou-se, neste trabalho, avaliar a população de juvenis do segundo estádio (J2) de Meloidogyne incognita (Kofoid \& White) Chitwood, e sua infectividade após o manejo do solo e da água em casa-de-vegetação.

A área empregada no ensaio havia sido cultivada 
com tomateiro (Lycopersicon esculentum Mill. cv. Santa Clara) seguido de alface (Lactuca sativa L. cv. Regina), sob cobertura plástica, e apresentava alta infestação de $M$. incognita. O solo é argiloso do tipo Latossolo Vermelho com $69 \%$ de argila, $14 \%$ de silte e $17 \%$ de areia. No preparo da área para ser instalado o ensaio, os sistemas radiculares da alface foram arrancados e eliminados, sendo em seguida formados canteiros e estabelecidas parcelas com 1,44 $\mathrm{m}^{2}$ de área útil, constituindo-se a unidade experimental. Foram estabelecidos quatro tratamentos a saber: 1) solo revolvido e irrigado; 2) solo revolvido e sem irrigação; 3) solo não revolvido e irrigado e 4) solo não revolvido e não irrigado, considerado testemunha, em seis repetições, em delineamento em blocos ao acaso. $\mathrm{O}$ solo foi revolvido com trator Agrale, modelo 4100, utilizando-se rotoencanteiradora de $1,2 \mathrm{~m}$ de largura e $20 \mathrm{~cm}$ de profundidade, deixando-se o solo bem solto e destorroado. Nos tratamentos com irrigação, logo após o revolvimento do solo, aplicaram-se $10 \mathrm{~mm}$ de lâmina de água, manualmente, utilizando-se regador.

O ensaio foi iniciado em período de temperatura do ar de $26^{\circ} \mathrm{C}$ pela manhã e umidade do solo em $12 \%$ na camada de 0 a $18 \mathrm{~cm}$ de profundidade.

A população de M. incognita foi avaliada no início do estabelecimento do ensaio, aos sete dias e 14 dias após. Para isto foram feitas amostragens em três pontos distintos dentro de cada parcela, cujas amostras foram reunidas formando uma composta de $500 \mathrm{ml}$ de solo. Utilizou-se essa amostra para se avaliar o número de $\mathrm{J} 2$ por meio da técnica de Jenkins (1964), fazendo-se duas extrações (100 g cada) e usando-se a média para comparar os resultados. Também, avaliou-se a população total infectiva (juvenis e ovos), dessas amostras, empregando-se bioteste com tomateiro do cultivar Santa Clara. Para isto, cada célula de bandejas de isopor recebeu uma mistura de $50 \mathrm{ml}$ de substrato Plantmax ${ }^{\circledR}$ e $50 \mathrm{ml}$ do solo da amostra composta, com duas repetições por parcela. A seguir, semearam-se sementes de tomateiro (Lycopersicon esculentum Mill. cv. Santa Clara I 5900) em bandejas, as quais foram mantidas em casa-de-vegetação apropriada para à produção de hortaliças, com irrigação por nebulização. Quarenta e cinco dias após a semeadura, cortou-se a parte área dos tomateiros, e as raízes foram separadas do solo e lavadas em água. As massas de ovos foram coradas com solução aquosa de Floxina B 0,0015\% e contadas para se estimar a população total infectiva de $M$. incognita na amostra.

Os dados relativos aos números de $\mathrm{J} 2$ por $100 \mathrm{~cm}^{3}$ de solo e de massas de ovos por sistema radicular foram transformados em $\sqrt{x \quad 0,5}$ e as médias comparadas pelo teste de Scott \& Knott (1974). As análises foram realizadas pelo programa SISVAR.

A população de $\mathrm{J} 2$ no solo, avaliada pela técnica de Jenkins (1964) e pela população total infectiva, avaliada pelo bioteste, foram semelhantes $(\mathrm{P} \leq 0,01)$ entre todos os tratamentos no início do estabelecimento do ensaio (Figuras 1 e 2). Sete dias após, ocorreu redução significativa $(\mathrm{P} \leq 0,01)$ do número de $\mathrm{J} 2$ no solo apenas revolvido (Figura
1), enquanto a população total infectiva de $M$. incognita foi significativamente reduzida $(\mathrm{P} \leq 0,01)$ apenas quando o solo foi revolvido e irrigado, simultaneamente (Figura 2).

O revolvimento do solo reduziu a população de J2 (Figura 1), mas não a população total infectiva (Figura 2), provavelmente devido, à sensibilidade do $\mathrm{J} 2$ ao ressecamento provocado pelo revolvimento e, conseqüentemente, a resistência dos ovos a esse tipo

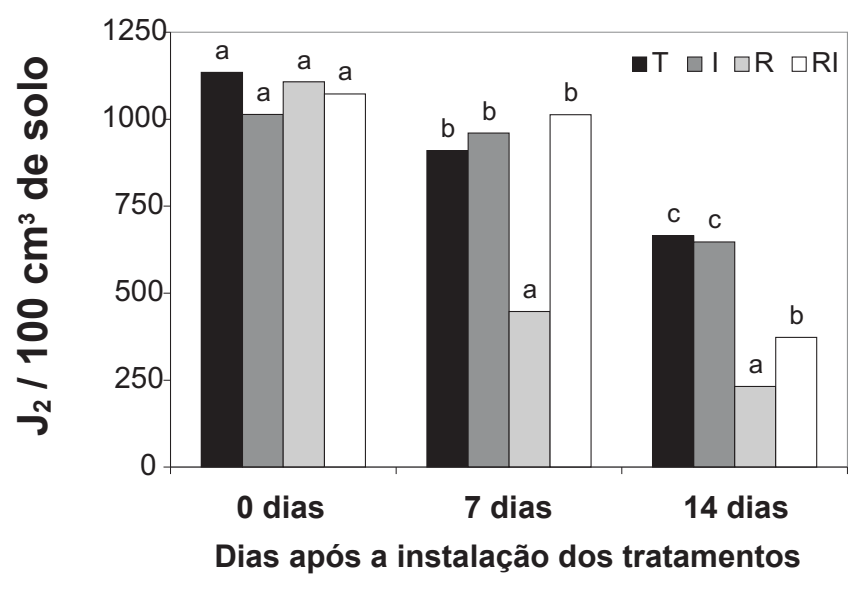

FIG. 1 - Número de juvenis do segundo estádio (J2) de Meloidogyne incognita por $100 \mathrm{~cm}^{3}$ de solo colhido em casa-devegetação aos zero, 7 e 14 dias após o revolvimento do solo (R), seguido de irrigação (RI), apenas irrigado sem revolvimento (I) ou sem irrigação e revolvimento (T), após a instalação do ensaio. Barras seguidas pela mesma letra não diferem, significativamente, entre si pelo teste de Scott \& Knott (1974), a 1\% de probabilidade $(\mathrm{CV}=10,14)$.

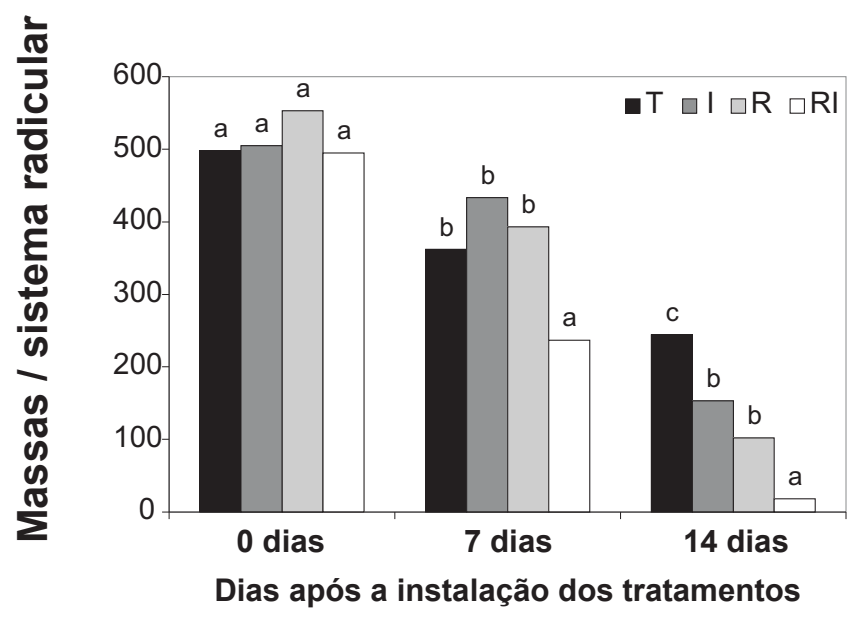

FIG. 2 - População total de Meloidogyne incognita no solo, avaliada pelo bioteste com tomateiro, expressa em número de massa de ovos por muda no momento do estabelecimento do ensaio, aos 7 e 14 dias após o revolvimento do solo (R) e seguido da irrigação (RI), apenas irrigado sem revolvimento (I) ou sem irrigação e revolvimento (T). Barras seguidas pela mesma letra não diferem, significativamente, entre si pelo teste de Scott \& Knott (1974), a 1\% de probabilidade $(\mathrm{CV}=11,36)$. 
de manejo do solo. A irrigação após o revolvimento, restabeleceu o teor de umidade mantendo alta a população de J2 no solo revolvido (Figura 1). Entretanto a população de $\mathrm{J} 2$ perdeu $(\mathrm{P} \leq 0,01)$ parte dessa capacidade infectiva nesse período de sete dias sem hospedeiro (Figura 2), sugerindo perda de lipídios. Van Gundy et al. (1967) verificaram perda na infectividade relacionada com redução de 50 a $60 \%$ das reservas energéticas lipídicas de J2 de M. javanica (Treub) Chitwood.

Aos 14 dias após o estabelecimento do ensaio, o número de $\mathrm{J} 2$ no solo revolvido e no solo revolvido e irrigado, teve comportamento semelhante em comparação ao de sete dias, porém nas parcelas revolvidas e irrigadas o número de $\mathrm{J} 2$ foi menor $(\mathrm{P} \leq 0,01)$ do que nas testemunhas ou apenas irrigado (Figura 1). Nesse mesmo período, a infectividade do inóculo nas parcelas revolvidas e irrigadas foi a menor $(\mathrm{P} \leq 0,01)$ dentre todos os tratamentos, chegando a $96 \%$ de redução em relação ao controle (Figura 2), demonstrando novamente perda da infectividade de parte da população de J2, como já discutido. Observou-se também nesse período, a redução significativa $(\mathrm{P} \leq 0,01)$ do inóculo infectivo quando as parcelas foram apenas irrigadas, comparadas à testemunha (Figura 2). Muito provavelmente a irrigação possibilitou maior movimentação do J2 e conseqüente perda de lipídio reduzindo infectividade. Também, a boa oxigenação no interior do solo deve ter incrementado o movimento do $\mathrm{J} 2$ já que se fez apenas uma irrigação. $\mathrm{O}$ excesso de umidade no solo induziria a quiescência levando a sobrevivência (Starr, 1993), reduzindo assim a eficácia da irrigação como tática de controle desses patógenos em ambientes protegidos. Portanto irrigações intermitentes não deveriam ser recomendadas quando se pretende usá-la como método de controle de M. incognita. Dutra \& Campos (2003a, b) e Dutra et al. (2003) obtiveram altas produções de feijão (Phaseolus vulgaris L.), alface (Lactuca sativa L.) e quiabo (Hibiscus esculentus L.) e redução acentuada da densidade populacional de Meloidogyne incognita em áreas altamente infestadas quando revolveram e irrigaram o solo 14 dias antes da semeadura.

Embora não fosse objetivo desse ensaio, observouse decréscimo populacional de $M$. incognita ao longo do período de 14 dias de alqueive em todas as parcelas, com decréscimo mais elevado na infectividade do inóculo (Figuras 1 e 2). A infectividade do $\mathrm{J} 2$ na ausência do hospedeiro após sete dias é altamente reduzida quando o solo é revolvido seguido de uma única irrigação, podendo assim constituir-se numa tática de controle de
M. incognita em ambiente protegido em condições de temperatura elevada e de alqueive por 14 dias.

\section{REFERÊNCIAS BIBLIOGRÁFICAS}

CAMPOS, V.P. Sobrevivência de Meloidogyne javanica no solo e em raízes de tomateiros. Summa Phytopathologica 13:191-196. 1987.

BURIOL, G.A., SCHNEIDER, F.M. \& ESTAFANEL, V. Modificação da temperatura mínima do ar causada por estufas de polietileno transparente de baixa intensidade. Revista Brasileira de Agrometerologia 1:43-49.1993.

DI VITO, M.N.G. \& CARELLA, A. Population densities of Meloidogyne incognita and yield of Capsicum annum. Journal of Nematology 17:45-49. 1985.

DUTRA, M.R. \& CAMPOS, V.P. Efeito do manejo de solo e da irrigação como nova tática de controle de Meloidogyne incognita em feijoeiro. Fitopatologia Brasileira 28:608-614. 2003a.

DUTRA, M.R. \& CAMPOS, V.P. Efeito do manejo de solo e da água na população de Meloidogyne javanica em quiabeiro no campo. Summa Phytopathologica 29:249-254. 2003 b.

DUTRA, M.R., CAMPOS, V.P. \& TOYOTA, M. Manejo do solo e da irrigação para o controle de Meloidogyne javanica em alface. Nematologia Brasileira 27:29-34. 2003.

JENKINS, W.R. A rapid centrifugal-flotation technique for separating nematodes from soil. Plant Disease Reporter 48:692. 1964. (Abstract)

MADULU, J.D. \& TRUDGILL, D.L. Influence of temperature on the development and survival of Meloidogyne javanica. Nematologica 40:230-243. 1994.

MEDEIROS, L.A.M., MANFRON, P.A., MEDEIROS, S.L.P. \& BONNERCARRÈRE, R.A.G. Crescimento e desenvolvimento da alface (Lactuca sativa L.) conduzida em estufa plástica com fertirrigação em substratos. Ciência Rural 31:199-204. 2001.

SCOTT, A.J. \& KNOTT, M. A cluster analysis method for grouping means in the analysis means in the analysis of variance. Biometrics 30:507-512. 1974.

SCHNEIDER, F.M., BURIOL, G.A. \& ANDRIOLO, J.L. Modificação na temperatura do solo causada por estufas de polietileno de baixa densidade em Santa Maria, RS. Revista Brasileira de Agrometerologia 1:37-42. 1993.

STARR, J.L. Recovery and longevity of egg masses of Meloidogyne incognita during simulated winter survival. Journal of Nematology 25:244-248. 1993.

VAN GUNDY, S.D., BIRD, A.F. \& WALLACE, H.R. Aging and starvation in juvenile of Meloidogyne javanica and Tylenchulus semipenetras. Phytopathology 57:559-571. 1967. 